\title{
As Congregações de Notre-Dame de Sion: superioridade masculina e subordinação feminina na Igreja católica ${ }^{1}$
}

\author{
Angela Xavier de Brito*
}

\section{Resumo}

As duas congregações de Notre-Dame de Sion, fundadas na França por Théodore Ratisbonne com dez anos de intervalo, possuem uma comunidade de nome e objetivo, assim como uma regra bastante análoga. Seu desenvolvimento foi, entretanto, bastante diferente. Segundo os critérios da época, a obra de conversão dos judeus não poderia ser exclusivamente feminina. Os padres de Sion foram, então, criados para se dedicar ao apostolado

* Pesquisadora associada ao CERLIS, Universidade ParisDescartes/Centro Nacional da Pesquisa Científica (CNRS), Paris, França. axavierdebrito@gmail.com direto do carisma congregacional, mas se desenvolveram com dificuldade a partir de 1925 e adotaram uma orientação conversionista. Já a congregação feminina se afastou progressivamente desse carisma, consagrando-se, com a anuência do fundador, ao ensino das elites. Enquanto as irmãs se submeteram às determinações da hierarquia católica, que as destinavam ao apostolado indireto, as relações entre as congregações decorreram harmoniosamente. 0 conflito entre elas estalou nos anos 1960, quando as irmãs decidiram investir no campo intelectual e teórico, tradicionalmente reservado ao sexo masculino durante séculos.

\section{Palavras-chave}

Gênero, igreja católica, congregação, carisma, campo intelectual. 


\title{
Our Lady of Zion's Congregations: Male Dominance and Women Subordination within the Catholic Church
}

\begin{abstract}
The two congregations of Our Lady of Zion, founded in France by Théodore Ratisbonne with a ten years intermission, have a community of name and objective, as well as a most similar rule. Their development is nevertheless quite different. According to the epoch's criteria, women only could not operate the conversion of Jews. The Zion's priests are then founded to put forth a direct apostolate, but their development is quite strenuous, which begins in 1925 with a conversionist emphasis. As for the women's congregation, it moves progressively away from this charisma and consecrates itself to feminine elite education. While the sisters submit to the determinations of the Catholic hierarchy, which vows them to an indirect apostolate, the relationships between the two congregations progress harmoniously. The struggle between them takes place in the 1960's, when the sisters invest the intellectual and theoretical field, traditionally reserved for centuries to the male gender.
\end{abstract}

Keywords Gender, catholic church, congregation, charisma, intellectual field. 


\section{Introdução}

As congregações das irmãs e dos padres de Notre-Dame de Sion, fundadas ambas na França por Théodore Ratisbonne, com cerca de dez anos de intervalo, possuem o mesmo carisma, sem que as irmãs sejam submetidas "à jurisdição dos Padres" (Comte, 2002, p.103). Mas as interações que elas teceram entre si, ao longo de seu desenvolvimento, as fizeram estreitamente interdependentes. No século XIX, na Igreja ou na sociedade civil, as mulheres eram uma minoria social que foi, durante muito tempo, constituída como categoria à parte, com frequência dentro dos marcos dos estudos de gênero. Hoje em dia, a maioria das estudiosas do feminismo sabe que, "como os homens e as mulheres se definem em termos recíprocos" (Scott, 1988, p. 42), a compreensão de cada um deles requer uma análise comparativa.

A congregação feminina de Notre-Dame de Sion faz parte dessas congregações “úteis”, dotadas de uma superiora geral, que proliferaram no século XIX. Desde sua fundação, ela possuiu os atributos da continuidade (noviciado) e do poder (casa generalícia); seus membros adotaram uma regra de vida específica, definida pelo fundador e reconhecida pela Igreja. De direito pontifício, sua expansão foi relativamente rápida, numa conjuntura em que as freiras eram "mais numerosas do que o clero masculino" (Langlois, 1984, p.14-15). Já a congregação masculina, de direito diocesano, penou para se desenvolver, a ponto de desesperar seu fundador. Ao ilustrar a forte presença das mulheres dentro da Igreja, as congregações femininas são, também, testemunho de sua luta por uma vida ativa num período em que isso era reservado aos homens, assim como de seus embates com uma hierarquia eclesiástica totalmente masculina por privilégios que eram somente atribuídos aos padres.

\section{A fundação da congregação feminina}

Alguns dados sobre o fundador e a história das duas congregações contribuem para esclarecer suas dinâmicas diferentes, ligadas à problemática do gênero. Tanto Théodore Ratisbonne quanto seu irmão Alphonse eram "judeus convertidos descendentes de uma família de personalidades alsacianas” (Comte, 2002, p.102). Théodore pertencia aos Padres de Saint Louis, círculo de intelectuais judeus convertidos por Louis Bautain e Louise Humann. Como os padres se dedicavam ao ensino para meninos em Estrasburgo, Louise Humann quis estender a obra às meninas, criando as Dames de Saint Louis (Aron, 1936, p. 56-57), às quais pertenciam a viúva Sophie Stouhlen e Louise Weywada, de quem Théodore era diretor de consciência. 
Em 1842, em Paris, Théodore se tornou capelão do orfanato da Providência e, por sugestão de Alphonse, decidiu criar ao lado deste um catecumenato para meninas judias pobres. Ele convocou Sophie e Louise para essa tarefa e, habituadas a obedecer em tudo a esse "homem de oração e de comando" (Aron, 1936, p. 51), ambas vieram encontrá-lo em Paris. Sua franca adesão permitiu que Théodore colocasse a pedra fundamental no catecumenato, ao receber as filhas da Sra. Würmser, judia que ele convertera ao catolicismo. Em 1843, Gregório XVI aprovou seu pedido de trabalhar para a conversão dos judeus. Nesse mesmo ano, ele se tornou superior geral da congregação feminina de Notre-Dame de Sion e abriu o primeiro internato para meninas - que, três anos mais tarde, contaria 30 alunas internas e 80 externas (Aron, 1936, p. 63). Sophie e Louise integraram essa congregação, apesar de a conversão dos judeus pouco lhes dizer respeito. No entanto, cedendo ao espírito da época, oito anos mais tarde, Théodore atribuiu à congregação uma superiora geral, conservando “apenas a responsabilidade de diretor espiritual e de conselheiro" (Aron, 1936, p.78). Na verdade, apesar das sucessivas irmãs superioras, de 1851 até sua morte², foi ele, praticamente, quem orientou a congregação. Sua presença foi constante entre as primeiras irmãs, que "desejam conservar seu espírito e transmiti-lo à geração seguinte" (Giraud, 1999, p. 9). Foi ele quem tomou as principais decisões institucionais, quem designou Madre Sophie Stouhlen como primeira superiora geral e nomeou Louise para sucedê-la. Foi ele quem redigiu, em 1947, as Regras e Constituições da congregação. Foi ainda ele quem se opôs, em 1865, à criação de outro noviciado "para preservar a unidade de espírito" de Sion (Giraud, 1999, p. 3-7).

\section{0 desenvolvimento da congregação feminina}

Em 1847, Pio IX reconheceu oficialmente "a pia comunidade de senhoras reunidas sob a proteção de Notre-Dame de Sion, com o objetivo de trabalhar com ardor à conversão dos judeus e à instrução das catecúmenas” (Aron, 1936, p. 75). O Conselho de Estado lhes outorgou reconhecimento oficial em 1856. A Igreja se revelou mais lenta: a Congregação de Propaganda da Fé só emitiu o decreto de aprovação por dez anos da Regra constitutiva de Notre-Dame de Sion em 1863; a aprovação definitiva de Roma só ocorreu em 1874 (Aron, 1936, p.78).

A partir do final do século XIX, os "talentos educativos" de Madre Rose Valentin

2. Théodore morreu em 10 de janeiro de 1884; seu irmão, o Père Marie, em 6 de maio do mesmo ano. "imprimiram irresistível impulso à criação dos internatos” (Aron, 1936, p. 80). Atendendo à deman- 
da social da época, as irmãs se consagraram com sucesso à educação de certas frações das elites femininas. "A personalidade carismática de seu fundador e o renome das religiosas como excelentes educadoras" (Comte, 2002, p.103) conferiram certa reputação aos internatos de Paris e de Grandbourg. Aumentou o número de alunas pertencentes a "famílias social e politicamente importantes" (Isser; Schwartz, 1986, p. 12), o que contribuiu "para equilibrar as finanças da congregação e, sobretudo, para conseguir um recrutamento de qualidade" (Langlois, 1984, p. 481-482). A congregação passou de 57 irmãs, em 1853 (Aron, 1936, p.77), a 381 membros em 1878 (Congrégation des Sœurs de Notre-Dame de Sion, 1936)³.

Solidamente implantada na França, Notre-Dame de Sion desenvolveu, entre 1843 e 1884, no exterior, uma rede de 13 internatos de elite (Mondésert, 1956) que the permitiu figurar entre as três primeiras congregações com a maior renda per capita (Langlois, 1984, p. 384). As sucursais do exterior chegaram mesmo a receber financiamento do governo francês, por serem consideradas "um agente eficaz de difusão da língua e da cultura francesa” (Petitjean, 1996, p. 97). Os dotes bastante elevados das postulantes, as mensalidades dos internatos e dos colégios que dirigiam, os donativos e os investimentos em propriedades que lhes rendiam aluguéis (Fonseca, 2009) deixaram as irmãs numa situação financeira bastante confortável.

A atividade docente da congregação parecia afetar sua dedicação ao carisma, mas sua pouca atenção à conversão dos judeus não se fez sem a anuência de Théodore. Em uma brochura de 1845, ele apresentou a congregação feminina como "uma associação de orações para a conversão de Israel" e evocou o papel dos "internatos [...] para jovens cristãs" como um "campo de atividade para as Senhoras da comunidade e como um recurso onde colocar as neófitas" (Aron, 1936, p.64-65). As Lettres Sioniennes abundam de catecismos, abjurações, conversões e batismos, mas a participação das irmãs nesses ritos se reduzia à sua mera presença física, pelos limites com que a Igreja até hoje cerceia as mulheres. E não por culpa delas: no Capítulo de 1925, Madre Théodorine, responsável da API ${ }^{4}$, reclamou insistentemente uma ação direta junto aos judeus (Giraud, 1999, p.17), o que seu estatuto de semienclausuradas não permitia. Não se trata de que, "absorvidas por sua atividade nos grandes internatos na França, na Europa central, nos países mediterrâneos e anglo-saxões e até mesmo na América Latina" (Comte, 2002, p.103), as irmãs "tivessem esquecido" o carisma da congregação.

3. 0 Censo geral das congregações de 1878 registra apenas 140 irmãs (Langlois, 1984, p. 384).

4. A Association de Prières pour la conversion de Israël foi uma associação prosélita ligada a Sion de 1903 a 1966. 
Trata-se de que, "apesar do carisma da congregação, as Senhoras de Notre-Dame de Sion dedicaram-se desde sua origem à educação" (Aron, 1936, p. 80), porque lhes fora atribuído, desde a fundação, um papel indireto no apostolado de Israel. Elas nada mais fizeram do que aquiescer àquele que consideravam "seu pai”, de quem eram as “filhas amantes e obedientes", segundo a metáfora familiar. A história de Sion mostra que a congregação feminina foi criada como um recurso auxiliar, para ter um papel secundário, não ativo, na conversão dos judeus - meta que "só poderia ser atingida com a fundação de uma Sociedade de padres missionários” (Aron, 1936, p. 41).

\section{A Sociedade dos padres missionários de Notre-Dame de Sion}

Pelos critérios da época, "uma obra cujo objetivo era a salvação de Israel não podia nem devia ser exclusivamente feminina” (Aron, 1936, p. 89), pois, por melhor que fosse, estaria incompleta sem a existência dos padres. Por isso, "há já algum tempo, Notre Père sonhava seriamente em começar a obra dos pequenos neófitos, tanto mais que muitos colaboradores se apresentaram para ajudá-lo” (Congrégation des Sœurs de Notre-Dame de Sion, 1852). Théodore Ratisbonne queria, sobretudo, "abrir um colégio de meninos que pudesse servir de neofitato para jovens israelitas", que permitisse recrutar "um grupo de missionários [...] inteiramente devotado à conversão dos Judeus" (Aron, 1936, p. 87). Como clérigos regulares, os padres poderiam se dedicar a tarefas educativas, intelectuais e missionárias, além do ministério pastoral. 0 Cardeal Barnabo, prefeito da Propaganda da Fé, o estimulou nesse sentido, declarando, em 1863, que, "se a Santa Sé aprovou a congregação das religiosas, com muito mais razão aprovará a ordem sacerdotal dos padres de Sion” (Ratisbonne, 1863). Antes mesmo que a congregação masculina viesse a ter existência real, o Cardeal Fransoni lhe enviou em 1852, uma patente de louvor, coisa que as irmãs só receberam quatro anos após sua fundação. Certamente, uma congregação masculina desfrutava de maiores vantagens. Primeiro, não havia restrições de movimento para os padres, contrariamente às muIheres, que não podiam sair sozinhas ou pernoitar fora de casa. Segundo, eles podiam catequizar, batizar e dar os sacramentos àqueles que convertiam, o que era vedado às mulheres. Terceiro, numa época em que o acesso aos estudos era francamente desigual, os padres tinham melhor preparação teórica. Last but not least, o acesso ao púlpito ampliava seu âmbito de ação. Théodore não tinha pejo em onerar suas filhas com o custo de seus sonhos. A casa que the convinha foi comprada pelas irmãs, que pagaram os 47.000 francos pedidos pelo proprietário, além dos 600 francos da promessa de venda. 
A casa de Saint Pierre foi instalada e bem, tanto quanto nossas finanças o permitiam. É a casa de Nossa Senhora de Sion que, até o presente, provê suas necessidades. Como a Santa Virgem cuidou e alimentou o Menino Jesus, assim Nossa Senhora de Sion mantém Saint Pierre até que este, por suas forças, consiga andar sozinho (Congrégation des Sœurs de Notre-Dame de Sion, 1852).

A mudança de registro é interessante. Apoderadas pela função econômica, as irmãs se sentiram autorizadas a inverter o jogo: de "filhas", elas passaram a "mães provedoras", equiparando-se à "Santa Virgem"; a congregação dos padres era o "Menino Jesus", que ainda não tinha "forças para andar sozinho". A proteção das irmãs duraria muito tempo, devido à incapacidade dos padres de se estabilizar e ganhar seu próprio sustento. A Sociedade masculina teve um “desenvolvimento lento”, "era pouco numerosa”, "nunca foi legalizada" e "nunca se consagrou ao ensino" (Colson, História, s.d., p. 21-23). Dos quatro prédios onde os padres se alojaram, de sua fundação até hoje, a casa da rue Duguay-Trouin e o 68 bis, rue Notre-Dame des Champs pertenciam às irmãs e lhes foram cedidos por elas (Colson, História, s.d., p. 210).

Quando Théodore apresentou ao arcebispo de Paris as Constituições da Casa de Saint Pierre, escritas por ele mesmo, não existia propriamente uma comunidade de padres de Sion: havia apenas o noviço Bonytand e mais um padre, que "estava apenas de passagem" (Colson, 1959, p. 2). Ela acolheu três crianças: o jovem Louis-Alphonse Samuel, dito Demarc, filho de Sarah Picard, judia convertida por Théodore; Stanislas e Adolphe Berkowitz, de 6 e 13 anos, "filhos de um coronel polonês israelita morto no campo de batalha” (Congrégation des Sœurs de Notre-Dame de Sion, 1852). Mas Théodore "escreve ao Cardeal Lambruschini, em Roma, para participar-lhe a fundação da Casa de Saint Pierre e rogar que Sua Eminência obtenha a bênção do Santo Padre para esta obra” (Colson, História, s.d., p. 3). Ele foi a Roma no mês seguinte, para "conhecer as intenções do Santo Padre sobre a fundação da comunidade de Saint Pierre, sua forma, suas Regras, suas Constituições" (Ratisbonne, 23/11/1852).

\section{A ação insidiosa do gênero}

Conforme "o grupo de Senhoras se desenvolve”, elas mesmas pediram a Théodore que fundasse para elas uma instituição religiosa formal (Giraud, 2003, p.14-15; Klein, [196-], p. 3). Habituadas a obedecer a seu diretor de consciência, elas aceitaram 
sem tergiversar as Regras e as Constituições redigidas por ele, mostraram-se prontas a se engajar na realização dos desejos do fundador. Mulheres do século XIX, ainda imunes aos anseios de autonomia que começavam a despontar em certas camadas sociais, sentiam-se mais seguras, quando abrigadas sob as asas mais amplas dos homens, numa Igreja que conferia às mulheres um status inferior. Todas as iniciativas eram tomadas pelo fundador ou seus delegados, inclusive a ida a Roma para negociar a aprovação de suas próprias Constituições (Colson, 1959, p. 4).

Mais seguros de si, os homens hesitaram bem mais em acatar as decisões de Théodore. No início, eles preferiram formar apenas uma "sociedade", e foi a esse título que se deu sua primeira ereção canônica, em 1855. Eles só iriam tornar-se uma congregação 40 anos mais tarde, por ocasião da reunião do Primeiro capítulo geral. Os votos sempre foram o calcanhar de Aquiles da Sociedade dos padres. A primeira proposta de votos, feita por Théodore em 1861 "para assegurar a continuidade da sociedade e prevenir-se contra certos padres levianos”, causou uma defecção generalizada, porque nenhum deles queria "abandonar as obras que dirigiam para comprometer-se cegamente com a visão do fundador” (Colson, 1959, p. 2). Pelo Regulamento de 1876, Théodore renunciou a impor votos à comunidade masculina, propondo-lhes "a união na caridade", um "trabalho de santificação pessoal” e "a prática evangélica das virtudes da pobreza, obediência e castidade” (Colson, História, s.d., p. 32-33). Mas, escaldado por acontecimentos anteriores, insistiu em acrescentar "uma promessa de estabilidade" seguida, um ano mais tarde, por "um ato de consagração" (Colson, História, s.d., p. 34) - "que no es lo mismo, pero es igual", diria Silvio Rodriguez (1975). Quando, em 1893, o Primeiro capítulo geral buscou consolidar a institucionalização, definindo votos por um ano e criando um noviciado, apenas os padres Givelet, Ledrappier, Diringer, De Chaumontel, Schaffner e Derwich acataram essa decisão. Os padres Dedoné, Decormis, Dupuis, Corneyre e Renard continuaram vinculados à congregação, sem se ligar por nenhum voto, e os demais se retiraram (Aron, 1936, p. 211). Em 1897, quando os seis padres pronunciaram seus votos perpétuos, a Regra foi modificada, para que os antigos membros que não tivessem prestado votos fossem sempre considerados padres de Sion.

\section{Três hipóteses}

Podem-se levantar algumas hipóteses quanto às dificuldades enfrentadas para fundar a congregação masculina. 
1. A primeira é que organizar homens em congregação provou-se mais complicado do que Théodore imaginara. Sophie e Louise, tão logo ele as chamou, se colocaram “em posição de poder vir o mais cedo possível a Paris" (Giraud, 2003, p. 13). Embora a comunidade inicial de irmãs tenha experimentado, como a sociedade masculina, "um vai-e-vem de chegadas e saídas" e tenha tido "certa dificuldade em se estabilizar", a obra era fecunda, várias vocações se manifestaram, como as de Flore Doutrelepont, Rose Valentin, Émilie Lagarmitte, Céline de Layens (Marie-Bénédicta, 1905, v. I, p. 415417). Em 1853, quando elas se instalaram na rue Notre-Dame des Champs, havia " 57 irmãs, incluindo as noviças" (Giraud, 2003, p.14-15), enquanto, dez anos depois de sua fundação, em 1862-1863, o número de padres oscilava entre oito e dez, a ponto de Théodore encarar a fusão com os Agostinianos como única solução possível.

Habituado a lidar com elementos dóceis e maleáveis, que adotavam sem questionar a visão de seu diretor de consciência, Théodore não sabia lidar com homens livres. Desejava, como um deus, moldá-los à sua imagem e semelhança. Como todo convertido, ele parece muito radical em sua concepção da verdade, desejando fazer da meta de sua vida aquela de toda uma congregação, sem concessões. Gostaria que todos os padres fossem jovens "humildes e devotados", como o Padre Dupuis, ou "home[ns] segundo o coração de Deus, anjo[s] de piedade e de fervor", como o Padre Courtade (Colson, História, s.d., p. 18 e p. 32). Mas a maioria desses padres, mesmo quando recém-saídos do seminário, tinha ideias assentadas sobre os rumos que queriam imprimir à sua vocação, e nem todos estavam dispostos a renunciar a suas ambições pessoais.

2. A segunda hipótese é que a adesão dos membros à congregação tenha sofrido o choque da personalidade do fundador. "Ao contrário de seu irmão, Théodore não é um condutor de homens, não possui nem seu realismo nem sua paciência” (Delpech, 1983, p. 349). 0 paternalismo e o autoritarismo, principais traços de seu caráter, certamente convinham mais ao trato com as mulheres. Apesar de carismático, Notre Père não sabia avaliar homens, não sabia dirigir por consenso. Mesmo a relação com seu irmão era complicada, apesar do amor que os unia. Père Marie deu-se rapidamente conta de que seu irmão queria instrumentalizá-lo, esperando que o secundasse, se ativesse às suas ordens, controlasse seu temperamento "impulsivo, ardente e audacioso", seu zelo "extravagante" (Aron, 1936, p. 48) e fizesse o que Théodore fora incapaz de fazer: "disciplinasse" a congregação masculina (Ratisbonne, 1966, p. 221). 0 marasmo de seus membros levou Notre Père a pensar seriamente em aceitar a proposta de fusão 
dos Agostinianos, apesar do risco de ver a comunidade de Sion perder "seu espírito e seu caráter particular [...] ao se unir a uma ordem antiga” (Colson, História, s.d., p. 21). A angústia de "chegar ao fim de [sua] vida sem ver essa comunidade sair da situação precária em que vegeta há vinte anos” (Colson, História, s.d., p. 25) fez com que Théodore se deixasse fascinar pelo Padre Jules Hugo, em quem ele via uma reprodução quase idêntica de si mesmo. Uma vez mais, sua falta de critério, sua precipitação, iriam Ihe trazer "uma de suas mais agudas decepções", ao perceber que este queria apenas tomar "a direção da obra” (Hugo, 1862) e impor à congregação suas próprias concepções. Na ânsia de recrutar, Théodore aceitava qualquer um na congregação e só depois constatava sua inadequação à vida religiosa, tal como ele a concebia. Ele recomeçava com outras pessoas, decepcionando-se mais de uma vez, culpando quem o abandonava, vendo "os padres partirem uns após os outros por razões fúteis" (Ratisbonne, 1966, p. 219). Apesar de se dizer "feliz por ter se livrado de confrades malcriados e mal intencionados que só procuram seus próprios interesses" (Colson, História, s.d., p. 36), ele achava quase impossível que essa congregação pudesse um dia "voar com suas próprias asas", mas ignorava as críticas que faziam os padres que abandonavam a Sociedade: "que não tínhamos futuro algum, que não tínhamos razão de ser, que as casas de nossas irmãs poderiam dispensar nossos serviços, que não fazíamos nada pela conversão dos judeus" (Colson, História, s.d., p. 25-26) - sem ver a parte que lhe incumbia nesse fracasso." Os poucos que ainda [lhe] permanecem fiéis" se dispersaram: Padre Renard partiu para Constantinopla, Padre Dupuis, para Alexandria, Père Marie, para Jerusalém" (Sion, História, s.d., p.16). Mas ele continuava querendo impor a todos sua vontade e suas regras, até que deixassem a congregação ou que morressem.

3. A terceira hipótese se refere ao status do carisma da congregação entre seus membros. Rota (2009, p.185) define três momentos distintos na relação da congregação de Sion com seu carisma. No primeiro, ela

assume seu apostolado segundo uma linha filosemita e conversionista; no segundo, depois da 2a guerra mundial, ela inscreve a relação da congregação com os Judeus na perspectiva do ecumenismo; o terceiro [...] a inscreve definitivamente, desde o Concilio Vaticano II, numa atitude de estima.

Irmãs e padres se comportavam, no entanto, de maneira diferente em cada uma dessas etapas. Na primeira, quando a Igreja adotou o antissemitismo teológico, que 
via nos judeus os assassinos do Cristo, as irmãs aceitaram a versão proposta por Théodore, sem questionar. Até 1950, ainda se encontravam, entre elas, irmãs que se referiam ao "deicídio cometido pelos judeus" (Klein, [196-], p. 5). Fundada para se ocupar do carisma apenas de forma passiva, "a inspiração original de recordar à Igreja a existência do povo judeu se torna secundária” (Klein, [196-], p. 5), e o ramo educativo acabou virando a atividade principal. Isso é menos compreensível no caso da Sociedade dos padres missionários, que "não tem colégios e não dirige na França nenhuma obra de ensino para meninos” (Colson, História, s.d., p. 45), limitando-se, com frequência, à função de capelães. A posição teológica da Igreja, que via o batismo como única saída para os judeus, não convencia todos os membros. Ainda nas primeiras décadas do século XX, mesmo os padres que pareciam mais comprometidos com a congregação, como o Padre Givelet, superior geral de 1893 a 1912, tinham dúvidas quanto à sua pertinência: o memorando que ele enviou a Roma, ao pedir demissão de seu cargo, "refletia a pouca confiança que tinha no apostolado de Israel e exprimia suas hesitações” (Aron, 1936, p. 212).

A descrição acima deixa a impressão de uma congregação masculina de grande fragilidade, que não atraía candidatos em número suficiente; cujo carisma, pouco prestigiado pela própria Igreja, não desfrutava de consenso sequer entre seus próprios membros. Mas Théodore desejava que a congregação masculina sobrevivesse a qualquer preço, mesmo às custas da perda de sua identidade. Até a morte do fundador, o desenvolvimento da Sociedade dos padres foi lento e errático. Enquanto a congregação das irmãs variava entre 57 e 600 membros entre 1853 e 1885 (Giraud, 1999, 2003), o número de padres oscilava entre 6 e 12, o que levou Théodore a dizer que sua "pedra funerária seria talvez, nos desígnios de Deus, o fundamento sobre o qual a Sociedade dos padres de Nossa Senhora de Sion deverá um dia se firmar e se estender" (Colson, 1959, p. 1). Palavras proféticas. Eles eram apenas nove quando os dois irmãos morreram em 1884, com meses de intervalo, e sua morte fez surgirem “divergências no espírito de muitos" (Siveton, 1903). O Nono capítulo geral, em 1931, constatou "um verdadeiro estado de deriva com relação às Constituições" (Rota, 2009, p. 2). Em 1884, Padre Courtade começou o processo de institucionalização que Théodore nunca conseguira levar a cabo, que Padre Ledrappier, seu sucessor, retomou em 1886. Finalmente, a fusão com a comunidade dos Clérigos de Saint-Sulpice permitiu aos Padres de Sion sua ereção canônica como congregação, em 1893. De 1853 a 1925, anos “marcados por hesitações, reveses e reviravoltas” (Aron, 1936, p. 
214), "os padres de Notre-Dame de Sion, totalmente absorvidos pela preocupação de existir e de preparar o futuro, [não puderam dar] atenção ao problema judeu" (Leroux, 1948, p. 4). Não é de espantar que a congregação fosse desconhecida por muitas pessoas, inclusive as alunas dos estabelecimentos femininos.

No entanto, não seria totalmente justo dizer, como o faz Rota (2009, p. 186), que ambas deixaram "em total abandono a obra especifica de Sion". As duas fizeram algo nesse sentido, embora essas poucas atividades tivessem claramente um sentido conversionista. Fiéis ao seu papel secundário de orar pela conversão dos judeus, as irmãs se encarregaram da API, cuja direção era atribuída, de direito, ao superior geral dos padres de Sion, e garantiram seu sucesso nos meios cristãos (Marx, 2005, p. 87; Rota, 2009, p. 187). Elas congregaram "os católicos que se preocupam com a salvação dos judeus nos marcos de uma teologia da substituição e de uma grande caridade" (Rota, 2003, p. 9). Elas editaram os Échos de Notre-Dame de Sion, órgão de difusão que contém relato de conversões de judeus, enviado trimestralmente "às boas almas [que] buscam neles uma razão para rezar” (Rota, 2009, p. 187-188). Quanto à congregação masculina, “um grupo muito limitado de padres [...] na paróquia adormecida de Issy-les-Moulineaux” (Rota, 2009, p. 186-187), sob a direção dos padres Colson e Leroux, se preocupava também com o carisma da congregação, sempre dentro de uma linha conversionista. Mas o arcebispo de Paris não favorecia o apostolado junto aos judeus e somente após sua morte, em 1920, padre Colson pôde realizar, durante mais de três anos, uma série de conferências sobre a história do povo judeu (Mazzarolo, 1965, p. 3). A eleição de Pe Théomir Devaux como superior geral, em 1925, daria aos padres melhores condições de dedicar-se ao apostolado efetivo de seu carisma, sempre entendido como a conversão dos judeus. Depois de tomar contato com uma série de personalidades interessadas pela questão judaica, o Pe Devaux (Carta de 06/07/1925) definiu que a congregação deveria "orientar-se definitivamente para o cumprimento de sua missão especial na Igreja”, relembrando à comunidade sua posição de "unificador dos espíritos em volta [desse] objetivo" central, que não toleraria "divergência de pontos de vista ou de apreciação a esse respeito" (Devaux, Carta de 08/12/1925).

\section{A luta dos gêneros pelo domínio da teoria}

Nesse contexto em que "a ordem social [...] repousa sobre uma estrita repartição dos papéis masculinos e femininos" (Mayeur, 1981, p. 49), as duas congregações começariam a disputar entre si o campo intelectual e teórico. É preciso não esque- 
cer que, durante o século XIX, as mulheres sempre foram mais prejudicadas no que se refere ao acesso ao conhecimento. Na França, até 1924, elas não tinham acesso ao baccalauréat, direito que fora dado aos homens desde 1808. 0 currículo dos internatos religiosos e mesmo o do ensino secundário laico para mulheres, criado em 1880 pela lei Camille Sée, “não contém nem latim nem filosofia” (Mayeur, 1981, p.50), afastando sistematicamente as jovens "do ensino mais elevado, das especulações próprias à filosofia” (Mayeur, 1981, p. 49). Se tantas mulheres escolheram entrar nos conventos durante o século XIX é porque, apesar de restringir sua liberdade de movimentos, estes lhes davam uma série de vantagens, maiores ou menores segundo a classe social, entre as quais a possibilidade de escapar à opressão masculina dentro do casamento; de aprender a ler e a escrever; de exercer uma profissão; e, mesmo, de ascender a postos de poder. Pergunta-se, no entanto, até que ponto essas instituições lhes permitiam adquirir novos conhecimentos ou aumentar seu domínio da abstração. Durante o século XIX e as primeiras décadas do século XX, a formação ministrada àquelas que escolhiam a carreira religiosa era bastante insuficiente. "Raríssimas irmãs possuíam um diploma qualquer” (Klein, [196-], p. 6). Esse era um dos pontos fracos dos internatos confessionais, quando o Estado buscou regulamentar o acesso ao professorado. Desde o fim do século XIX, “a lettre d'obédience não mais bastava para que uma religiosa pudesse se consagrar ao ensino" (Xavier de Brito, 2010, p. 144): no primário, exigia-se o ‘certificado de capacitação’ e, no secundário, o diploma de uma Escola Normal. Uma postulante detentora de um bom diploma poderia mesmo ser dispensada de dote. As que eram oriundas das classes altas já ingressavam nas congregações com certo nível de conhecimento, mas dispunham de pouco tempo para se especializar: na década de 1930, o noviciado das irmãs de coro de Sion previa apenas três horas de estudo por dia (Aron, 1936, p. 159).

Já a formação dos padres se articulava em três grandes etapas: o primeiro ciclo, de dois anos, lhes dava uma formação filosófica e bíblica fundamental, em que o latim era matéria obrigatória; o segundo ciclo, de três anos, associava uma formação sobre a Bíblia e as teologias fundamental, pastoral e moral; o terceiro ciclo era praticamente reservado à inserção pastoral. Para se especializar nos assuntos de seu interesse, os candidatos seguiam cursos nas universidades católicas, nas Faculdades de Teologia ou na Universidade gregoriana, em Roma. Assim, no campo cultural e teórico, os padres já partiam com vários corpos de avanço. Até o Concílio Vaticano II, os padres eram “os únicos a elaborar o saber teológico" (Nunes, 2009, p. 482). Só eles podiam 
“dispensar-lhes as graças do Santo Altar” (Congrégation des Sœurs de Notre-Dame de Sion, 1875), numa igreja cuja "ação religiosa era centrada em torno dos sacramentos” (Nunes, 2009, p. 491). O capelão era figura indispensável, escolhido, em geral, no caso de Sion, entre os padres da mesma congregação, por comodidade ou porque havia um contrato implícito de solidariedade entre eles. A relação entre os padres e as irmãs constituiu objeto de preocupação em todos os tempos: em 1928, Pio XI já se interessava pelo assunto (Mazzarolo, 1965, p. 4); e o Capítulo geral de 1969-1970 incluiu a questão da “colaboração com os padres de Sion” (Giraud, 1999, p. 26).

0 padre Devaux organizou no 68 bis um centro de informação dotado de uma rica biblioteca, onde os padres davam conferências e organizavam círculos de estudo. Eles ofereciam "seu ministério, com solicitude paterna” às irmãs (Aron, 1936, p. 217), para melhor prepará-las à conversão dos judeus. A metáfora familiar continuava presente, porém, em sua posição de produtores do saber, os padres se arvoravam não em irmãos, mas em "pais" intelectuais das religiosas. Na melhor tradição de pais autoritários convencidos da justeza de suas posições, eles consideraram os Échos de Notre-Dame de Sion "intelectualmente insuficientes" e começaram a editar sozinhos, desde agosto de 1928, uma revista denominada La Question d'Israël, que combatia o antissemitismo em vigor nos meios católicos como "contrário ao espírito cristão porque destrói a esperança de conversão” (Rota, 2009, p. 188).

Durante a Segunda guerra, os nazistas invadiram a Casa matriz, confiscaram a biblioteca e proibiram a publicação da revista (Mazzarolo, 1956, p. 8). No entanto, a ocupação alemã daria um conteúdo mais concreto às missões de ambas as congregações. Pela primeira vez, os habitantes do 61 e do 68 bis trabalhariam juntos. 0 padre Devaux e algumas irmãs, sobretudo as Ancelles, procuraram salvar adultos e crianças judias, enfrentando a proibição de Me Amédée, superiora geral da época (Comte, 2001; 2002, p. 105-107). Na Bélgica, Pe Démann realizou “obra similar” (Devaux, s.d.). Uma vez mais, as irmãs se distinguiram: sete delas receberam a Medalha dos Justos entre as Nações em 2007 (Poynard-Hirsch, 2011); mas um só padre, Théomir Devaux, a recebeu, a titulo póstumo, em 1996.

\section{Da conversão à atitude de estima}

No pós-guerra, em 1947, os Pe Devaux e Leroux fundaram os Cahiers Sioniens, órgão “de apostolado intelectual” (Leite, 2007) onde a congregação masculina inicia uma tímida revisão de sua relação com o povo judeu, sempre na linha conversionista. 
Apenas em 1948, quando Paul Démann assumiu a direção, a revista adotaria uma leitura do carisma sionense, "destituída de qualquer perspectiva missionária” (Rota, 2009, p. 189), até sua desaparição em 1955. Pe Démann estava convencido de que a missão essencial da Igreja com relação a Israel devia ser pensada em termos de reconciliação (Congrégation des Pères de Notre-Dame de Sion, 2006). Segundo testemunho da época, ele se tornou "redator em chefe dos Cahiers Sioniens, seu principal autor e a única pessoa a recolher fundos" (Vermès, 2006, p. 87). Ele reuniu uma equipe de pesquisadores no Centro de Estudos, colocando igualmente sua documentação à disposição de toda pessoa interessada. Seu principal combate foi contra a linha conversionista em vigor dentro de sua própria instituição. As "oposições mais dissimuladas que francas" (Rota, 2009, p. 191) e as profundas incompreensões que sofreu nesse período, quando foi acusado de autoritário, promíscuo, "apóstata” (Colson, História, s.d., p. 196) e, até mesmo, de "traidor da Igreja e da congregação de Sion" (Vermès, 2006, p. 90-91), o fizeram deixá-la em março de 1963. Nem mesmo a declaração Nostra AEtate (Vaticano II, 1965), "relembrando o laço que une espiritualmente o povo do Novo Testamento à linhagem de Abraão", bastou para fazer com que os padres de Sion abandonassem a postura conversionista. Eles só reconheceriam as implicações teológicas e apostólicas da atitude de estima que Paul Démann defendia a partir do Capítulo geral de 1970.

Com as mudanças sociais da época, “a transformação da educação feminina se acelera, a distância com o mundo masculino se reduz", a legislação marca uma abertura pedagógica que beneficiaria as mulheres e "as diferenças em matéria de educação entre os dois sexos vão se atenuar, sem desaparecer" (Mayeur, 1981, p. 51). A congregação feminina contava agora com mulheres que "tiveram um papel ativo na Resistência" e que "se mostravam insatisfeitas com os objetivos imprecisos, o estilo de vida arcaico" (Klein, [196-], p. 10), a dedicação quase exclusiva ao ensino de moças das classes privilegiadas; e queriam dedicar-se a seu carisma. Rota (2005, p. 70) estima que foram "os padres de Sion [que deram] origem a esse impulso", mas minhas informações me autorizam a pensar que quem desempenhou o papel essencial nesse momento foi Me Marie Félix III, superiora geral de 1950 a 1963. Em 1961, ela escreveu a suas filhas uma carta onde dizia sem rodeios, "que um número muito maior de irmãs deveria consagrar mais tempo à sua vocação especial” (Klein, [196-], p. 10). No ano seguinte, outra carta sua incitava as irmãs a desempenharem um papel de maior relevância na sociedade; a se consagrarem à leitura de livros que requeriam uma 
compreensão atual do judaísmo; e a se dedicarem a altos estudos especializados de teologia, fazendo com que "a ideia de conversão e de reparação perd[esse] qualquer relevância” (Klein, [196-], p. 10). A cumplicidade de Paul Démann, com quem ela tinha muitas afinidades, era importante, mas até mesmo ele mantinha uma relação paternalista com a parcela da congregação feminina que aderia a suas ideias. Numa carta de 18 de setembro de 1955 , ele informou o superior da congregação masculina que “ouvira dizer que as irmãs tinham agora consciência de que não podiam prescindir dos padres no que se refere a Israel” (Rota, 2009, p. 191). Tudo indicava que as irmãs estavam realizando uma "evolução em direção a uma forma apostólica mais intelectual e empática” (Rota, 2005, p. 71). Mas a matéria intelectual sendo, ainda, como os sacramentos, o ganha-pão da congregação masculina, os padres não estavam prontos a renunciar sem luta a esses privilégios, em benefício das mulheres.

Nesse ínterim, começaram os trabalhos de preparação do Concílio Vaticano II, em que as irmãs de Sion se destacaram. Cinco delas - Marie-Bénédicte Salmon, Charlotte Klein, Hedwig Wahle, Mireille Gilles e Magda Manipoud - , dotadas de sólida preparação, foram indicadas "para introduzir no texto conciliar uma definição do povo judeu que the devolvesse seu justo lugar na visão cristã da salvação” (Salmon, 2002, p. 474). Consciente de que essa questão levantaria vivas objeções por parte de certos setores do Concílio, Ir. Marie-Bénédicte buscou o apoio do pastor Richard Molard e do Pe Hruby, considerado, nessa época, nos meios sionenses, “a única pessoa competente em matéria de estudos judeus" (Salmon, 2002, p. 475). A partir das propostas dessa comissão, as irmãs contataram os bispos participantes do Concílio passíveis de se interessar por tal projeto, visando a conquistar seu apoio e a mobilizá-los como porta-vozes de suas posições. Apesar de estimuladas por uma carta do Conselho geral de sua congregação (Sion, 1964), sua condição de mulheres as obrigou a seguir apenas pela imprensa as deliberações desse mesmo Concílio pelo qual elas se haviam tanto empenhado. Não encontrei relatos referentes à ação dos padres de Sion na preparação do Concílio. No documento sobre a História da congregação dos padres, que vai até 1967, este é apenas um elemento de contexto sem maior relevância.

As irmãs começaram a assumir certa capacidade de intervenção dentro da congregação e dentro da Igreja. Ousaram expressar “o desejo de que se pusesse um termo à discriminação, à inferiorização, ao silêncio e à exclusão que lhes eram até então impostas, mas também ao monopólio dos padres sobre o sagrado" (Veillette, 1995, p.257). Os documentos de preparação ao Capítulo geral de 1964 mostram que, ao 
abandonar "a preocupação com a conversão [dos judeus] pela compreensão e pelo estabelecimento de uma relação" (Marx, 2005, p. 92), a congregação das Irmãs estava dando uma "guinada histórica e teológica" (Klein, [196-], p. 1), realizando sua "virada apostólica" (Comte, 2002, p. 112). Esse trabalho, "feito por uma minoria de pioneiras", contou com a ação de "duas notáveis superioras gerais”, Me Marie Félix e Me Laurice; e a intervenção de "três conselheiras gerais, Ir. Edward, Ir. Marie-Dominique, Ir. Magda”. Essas mulheres excepcionais fizeram várias propostas de trabalho intelectual ativo dentro da congregação, como

realizar palestras para padres, professores e seminaristas; organizar publicações sobre o judaísmo; fazer encontros nacionais e internacionais sobre o assunto; dar às noviças uma preparação adequada; e criar em cada Província uma casa para as irmãs especialistas, cujo tempo e esforço seriam inteiramente devotados a este trabalho específico (Klein, [196-], p.11).

Ou seja, cansadas de assumir uma posição secundária e de depender dos padres em matéria intelectual e teórica, elas buscavam abrir caminho para que a Igreja católica "reservasse às mulheres um lugar justo". Mas "era ainda preciso sensibilizar o conjunto das irmãs" (Comte, 2002, p.112-113).

Em 1963, a congregação feminina sacudiu simbolicamente o jugo da congregação masculina, criando uma situação que afetaria profundamente as relações entre as irmãs e os padres. Um desses pontos de atrito é ligado à direção do Centro de estudos e documentação sediado no 68 bis, onde os padres habitavam. Como esse prédio pertencia à congregação das irmãs, Me Marie Félix III decidiu utilizar o Centro para a formação das irmãs no apostolado de Israel, colocando à sua frente uma irmã. Os padres viveram essa decisão como "um golpe totalmente inesperado, duro e injusto". Parecia-lhes inadmissivel que a superiora, até então mãe provedora, pusesse seus filhos "à porta do 68 bis", " retirando dos padres o uso da casa [...] que ocupavam há 75 anos". Mas a postura que mais thes doeu foi sua vontade de "colocar uma mulher à frente de uma obra de apostolado na qual os padres deveriam trabalhar" (Mazzarolo, 1965, p. 16), o que era, segundo eles, um verdadeiro "ocaso sionense" (Colson, História, s.d., p. 198). Trocando em miúdos, o fim da picada!

Houve uma troca de cartas inflamadas entre Me Marie Félix III e Pe Sabiá, que o superior da congregação masculina delegara para substituir Paul Démann na direção 
do Centro. O Pe Sabiá encheu suas cartas de palavras como "humilhação", "injustiça", "sacrifícios" e "violação de direitos" e reduziu o conflito que os opunha a um “triste jogo de interesses pessoais ou comunitários” (Sabiá, 1963a). O superior lhe ordenou deixar o 68 bis o mais cedo possível. Ele tentou ainda buscar uma solução para a crise, mas, no anteprojeto que redigiu, em maio de 1963, apesar de reconhecer que não havia "elementos atualmente disponíveis e preparados entre os padres de Sion" (Sabiá, 1963b), Pe Sabiá teve o desplante de propor colocar à frente do Centro "um padre de Sion”, reservando "a uma irmã de Sion” o segundo lugar. Prova de que os estereótipos custam a morrer.

Finalmente o arcebispo de Paris interveio, nomeando "um comité provisório limitado", que tinha por presidente Monsenhor Cazelles, de Saint Sulpice; Me Marie-Bénédicte Salmon, que representava as irmãs e Pe Francisco Sabiá, representante dos padres de Sion; além do Pe Hruby, diretor de estudos, e do Pe Braun, secretário. Ambos os contendores concordaram com essa proposição, embora o superior dos padres tivesse condicionado sua aceitação ao exame da situação do 68 bis, "do ponto de vista legal e moral", e ao claro estabelecimento dos "direitos respectivos dos padres e das irmãs". Os padres reivindicaram ainda o direito de posse do Centro e da revista, que "sempre dirigiram sozinhos"; e queriam "retomar o lugar normal de diretores logo que possível” (Sabiá, 1963b). Ou seja, a divergência se resumiu claramente a uma luta de poder contra a ingerência das irmãs em matéria intelectual, em que os padres se apropriaram sem pejo do trabalho realizado por Paul Démann, alguém que condenavam acerbamente.

\section{À guisa de conclusão}

Embora as duas congregações de Sion tenham "uma comunidade de nome e de objetivo, uma regra bastante análoga, um mesmo Pai fundador", os padres deviam introduzir uma "nota viril”, e as religiosas, uma "nota feminina". Estas se dobraram ao estereótipo, consagrando-se ao apostolado indireto, "que convém mais ao temperamento feminino"; os padres "assumem os riscos do apostolado direto" e "derramam as riquezas de sua meditação e de seus estudos através da palavra e do livro, da conferência e do jornal” (Aron, 1936, p.207-209). A Igreja reforça a hierarquia de gênero em seu seio, reservando aos homens "a ordenação sagrada” e o poder de conferir "os sacramentos" e de "aperfeiçoar [...] seus conhecimentos a respeito das coisas divinas e humanas" (Vaticano II, 07/12/1965a). Às reivindicações feministas 
que se levantavam em meados do século XX, ela responde com um endurecimento de posições, reiterando a proibição à ordenação das mulheres e fechando o debate, já que "esse ditame deve ser considerado definitivo por todos os fiéis", pois se deve "à sabedoria do Senhor do universo" (João Paulo II, 1994). Apenas os homens "exercerão publicamente em nome do Cristo a função sacerdotal” (Vaticano II, 07/12/1965a) — embora a Igreja Anglicana, fiel ao mesmo Deus, ordenasse mulheres desde novembro de 1992. "A tentativa de ordenação sagrada de uma mulher é um delito grave”, pelo qual "tanto quem tenta conferir a ordem sagrada, como a mulher que tenta recebê-la incorrem a excomunhão latæ sententia reservada à sede apostólica” (Congregação pela doutrina da fé, 2010). A Igreja justifica, assim, por "razões teológicas fundamentais", a separação de gêneros e a discriminação das mulheres.

Enquanto as irmãs aceitaram passivamente esse estado de coisas, as relações entre as duas congregações se desenvolveram harmoniosamente. 0 aparelho ideológico que os envolve é bem lubrificado: vai desde os textos da Igreja até as posições da hierarquia, passando pelos diretores de consciência e pelos capelães, fazendo-as depender cada vez mais dos padres, apesar de sua superioridade econômica. Globalmente, as irmãs se submetiam. O conflito estalou quando elas tentaram invadir a reserva de caça dos padres, a atividade intelectual e teórica. A rebelião coincidiu com o vento de renovação que soprava ao mesmo tempo sobre a sociedade, com o feminismo; e sobre a Igreja, com o Concílio Vaticano II que, embora não tratasse da ordenação das mulheres, levantou questões que favoreceram seu acesso ao conhecimento.

A declaração Nostra Atate (Vaticano II, 1965) afetaria, em sentidos diferentes, a prática das duas congregações. Fortalecidas pelo trabalho realizado antes e durante o Concílio, as irmãs se lançaram com ardor ao trabalho intelectual, publicando revistas, implicando-se nas relações judaico-cristãs a partir da sólida rede de contatos que seu trabalho lhes permitira constituir (Sidic-Paris, 2013). Elas chegaram a enfrentar a hierarquia, acusando de hipocrisia os bispos que sustentavam que a adoção pública de uma posição de estima não lhes proibia rezar em segredo pela conversão dos judeus (Klein, [196-], p. 12). Assim, a Congregação feminina “cresce na compreensão de seu carisma, amadurece sua vocação e propõe uma nova maneira de responder às inspirações de seu fundador" (Congrégation des Sœurs de Notre-Dame de Sion, Constituições, art. 3). Sua mudança de comportamento deixou os padres desarvorados. Os anos 1960 foram, assim, palco de embates que afetaram profundamente as 
duas congregações, quando, tomados de surpresa, os padres buscaram retomar as rédeas do poder a qualquer preço.

Mas as mudanças na sociedade e a expansão das congregações iriam alterar a relação de forças. Hoje em dia, a congregação feminina conta com 417 irmãs, repartidas em 22 países (Congrégation des Sœurs de Notre-Dame de Sion, 2010-11), enquanto a dos padres possui 43 membros e cerca de 20 aspirantes à vida religiosa, distribuídos em três países (Ribeiro, 2009). No entanto, ambas tentam manter um funcionamento mais equilibrado. Enquanto as irmãs reduziram o número de colégios e se empenharam na parte intelectual ligada a Israel, fazendo cursos superiores, especializando-se em história do judaísmo e criando centros de estudo, os padres se consagraram mais ao ensino e à atividade paroquial.

Sua atuação conjunta parece abrir novas perspectivas. Três comunidades de irmãs e padres de Sion fundaram em Israel um centro de acolhida para jovens do mundo inteiro, onde as irmãs apostólicas e, desde 2009, os padres de Sion participam do acolhimento; as irmãs contemplativas fazem o trabalho silencioso da casa, acompanhando-o de suas preces. Na aurora do governo de um novo papa, talvez todas as esperanças sejam permitidas. 


\section{Referências bibliográficas}

ARON, Marguerite. Prêtres et religieuses de Sion. Paris: Bernard Grasset, 1936.

COMTE, Madeleine. De la conversion à la rencontre. Les religieuses de Notre-Dame de Sion (1843-1986). Archives juives, Paris, n. 35, p. 102-119, 2002-1.

COMTE, Madeleine. Sauvetages et baptêmes. Les religieuses de Notre-Dame de Sion face à la persécution des Juifs en France (1940-1944). Paris: L'Harmattan, 2001.

DELPECH, François. Notre-Dame de Sion et les Juifs. Réflexions sur le Père Théodore Ratisbonne et sur l'évolution de la congrégation de Sion depuis les origines. In: DELPECH, François. Sur les Juifs. Études d'histoire contemporaine. Lyon: Presses Universitaires de Lyon, 1983. p. 321-371.

GIRAUD, Anne Thérèse nds. En marchant avec le Père Théodore. Notre-Dame de Sion, les prémices, les commencements. Lyon: Atelier Audiovisuel de Notre-Dame de Sion, janvier 2003.

GIRAUD, Anne Thérèse nds. Histoire des Chapitres Généraux. Lyon: Atelier audiovisuel de Notre-Dame de Sion, novembre 1999.

ISSER, Nathalie; SCHWARTZ, Lita Linz. Charismatic leadership: a case in point. Cultic Studies Journal, Florida, v. 3, n. 1, p.57-77, 1986.

LANGLOIS, Claude. Le catholicisme au féminin. Les congrégations à supérieure générale en France dans le XIXe siècle. Paris: Le Cerf, 1984.

LEROUX, Marcel nds. Les pères de Notre-Dame de Sion. Cahiers sioniens, Paris, n.3bis, p. 4-5, 1948.

MARIE-BENEDICTA nds. Le Très Révérend Père Marie-Théodore Ratisbonne (18021884). Fondateur de la Société des Prêtres de la Congrégation de Notre-Dame de Sion d'après sa correspondance et des documents contemporains. Paris: Librairie Veuve Ch. Poussielgue, 1905. v. I.

MARX, Paule. Israël et nous, la revue des sœurs de Notre-Dame de Sion de Paris de 1950 à 1965. Sens, Paris, p. 78-97, février 2005.

MAYEUR, Françoise. Garçons et filles du XIXe au XXe siècle; une éducation différente. Enfance, Paris, t. 34, n. 1, p. 43-52, 1981.

MONDÉSERT, Claude, s.j. Les religieuses de Notre-Dame de Sion. Lyon: Lescuyer, 1956.

NUNES, Maria José Rosado. Freiras no Brasil. In: DEL PRIORE, Mary; BASSANEZI, Carla (Org.). História das mulheres no Brasil. São Paulo: Contexto, 2009. p. 482-509. 
PETITJEAN, Patrick. Entre ciência e diplomacia: a organização da influência científica francesa na América Latina, 1900-1940. In: HAMBURGER, Amélia Império et al. (Org.). A ciência nas relações Brasil-França (1850-1950). São Paulo: EDUSP; FAPESP, 1996. p. 89-120.

POYNARD-HIRSCH, Céline. Justes parmi les nations. Lyon: Atelier audiovisuel de Notre-Dame de Sion, 2011.

RATISBONNE, Théodore nds. Mes souvenirs. Paris: Les presses monastiques, 1966.

RODRIGUEZ, Silvio. Pequeña serenata diurna. In: RODRIGUEZ, Silvio. Dias y flores. Cuba, 1975. CD Áudio

ROTA, Olivier. Une double fidélité. Évolution générale de la congrégation féminine de Notre-Dame de Sion dans sa relation aux Juifs (1946-1969). Sens, Paris, p. 67-77, février 2005 .

ROTA, Olivier. Les Pères de Sion. Une vocation spécifique assumée avec difficulté (1925-1970). Sens, Paris, p.184-196, mars 2009.

SALMON Marie-Bénédicte nds. La congrégation Notre-Dame de Sion en France, pendant le concile Vatican II. Sens, p. 472-487, sept./oct. 2002.

SCOTT, Joan. Genre: une catégorie utile d'analyse historique. Cahiers Genre et développement, Genève, p. 41-67, printemps 1988.

VEILLETTE, Denise. Quand le silence prend corps. Les femmes, de l'occultation à l'influence, changent la dynamique du champ religieux. In: VEILLETTE, Denise (Org.). Femmes et religion. Sainte Foy: Les Presses de l'Université de Laval, 1995. p. 249-289.

VERMĖS, Geza. Sur Paul Démann. Sens, n. 2, Paris, p. 85-92, 2006. Numéro spécial Hommage à Paul Démann.

XAVIER DE BRITO, Angela. L'influence française dans la socialisation des élites féminines brésiliennes. Le collège Notre-Dame de Sion à Rio de Janeiro. Paris: L'Harmattan, 2010.

\section{Entrevistas}

FONSECA, Giselda Rollemberg nds. Entrevista com a Ir. Gisa. São Paulo, 2009.

RIBEIRO, Donizeti Luís nds. Entrevista telefônica com Pe Donizeti Ribeiro, superior geral da Congregação dos Padres de Notre-Dame de Sion. Paris, 2009.

\section{Arquivos}

COLSON, Henri nds. História da congregação dos padres de Nossa Senhora de Sion 1852-1967. Arquivos informatizados dos Padres de Sion. Datilografado. 
COLSON, Henri nds. Padres de Nossa-Senhora de Sion, 1959. Arquivos informatizados dos Padres de Sion. Datilografado.

CONGRÉGATION DES PÈRES DE NOTRE-DAME DE SION. Relatório apresentado ao Capítulo Geral, agosto de 1931. Arquivos da congregação dos Padres de Sion.

CONGRÉGATION DES SEUURS DE NOTRE-DAME DE SION. Constitutions 1984. Archives des Sœurs de Sion.

CONGRÉGATION DES SEEURS DE NOTRE-DAME DE SION. Journal de la Maison de Paris, 1852. Arquivos informatizados dos Padres de Sion.

CONGRÉGATION DES SCEURS DE NOTRE-DAME DE SION. Lettres sioniennes de Grandbourg, de janvier 1875 à décembre 1946. Archives des Sœurs de Sion.

CONGRÉGATION DES S氏EURS DE NOTRE-DAME DE SION. Status 2009-2010 et 20102011. Roma, 2010, 2011.

CONGRÉGATION DES SEEURS DE NOTRE-DAME DE SION. Tableau général de la congrégation de Notre-Dame de Sion 1843-1936. Paris, Secrétariat général, 1936. Archives des Sœurs de Sion.

DEVAUX, Théomir nds. Cartas circulares de 6 de julho e de 8 de dezembro de 1925. Arquivos informatizados dos Padres de Sion.

DEVAUX, Théomir nds. Lettre sur la visite de la Gestapo au 68 et sur les enfants cachés, [1940]. Arquivos informatizados dos Padres de Sion.

DEVAUX, Théomir nds. L'œuvre d'Israël au 68. Arquivos informatizados dos Padres de Sion.

HUGO, Jules nds. Lettre à un correspondant, 1862. Arquivos informatizados dos Padres de Sion.

KLEIN, Charlotte nds. Da conversão ao diálogo. As irmãs de Sion e os judeus. Um paradigma das relações católico-judaicas?. Arquivos informatizados dos padres de Sion. [196-]. Datilografado.

MAZZAROLO, Ilario Augusto nds. Um obstáculo ao apostolado de Israel. Paris, 1965. Arquivos informatizados dos Padres de Sion.

RATISBONNE, Théodore nds. Lettre aux sœurs de Sion. Rome, le 23 novembre 1852. Archives des sœurs de Sion.

RATISBOnNe, Théodore nds. Lettre au Père Marie. Rome, le 8 août 1863. Arquivos informatizados dos Padres de Sion.

SABIÁ, Francisco Murilo nds. Lettre à Me Marie Félix, supérieure générale de la congrégation des Sœurs de Notre-Dame de Sion. Paris, le 25 mai 1963a. Arquivos informatizados dos Padres de Sion. 
SABIÁ, Francisco Murilo nds. Lettre à M. l'Archevêque coadjuteur de Paris, le 25 mai 1963b. Arquivos informatizados dos Padres de Sion.

SIVETON, Père s.j. Lettre au Pe Givelet, supérieur général de la congrégation des Pères de Notre-Dame de Sion. Louvain, 1903. Arquivos informatizados dos Padres de Sion.

\section{Internet}

CONGREGAÇÃO PELA DOUTRINA DA FÉ. Declaração De Gravioribus delictis, de 15 jul. 2010. Disponível em 〈http://www.vatican.va/resources/ resources_norme_po.html〉. Acesso em: 10 mar. 2013.

CONGRÉGATION DES PÈRES DE NOTRE-DAME DE SION. Informa-Sion. Bulletin Informatif des Religieux de Sion de Paris, Paris, n. 12, 2006. Disponível em : 〈http:// www.congregation-sion.org/IMG/pdf/Informa-Sion_12_Special_Paul_DEMANN.pdf〉. Acesso em : 04 mar. 2010

JEAN PAUL II. Lettre apostolique Ordinatio sacerdotalis, de 22 maio de 1994. Disponível em: 〈http://www.vatican.va/holy_father/john_paul_ii/apost_letters/documents/hf_ jpii_apl_22051994_ordinatio-sacerdotalis_fr.html〉. Acesso em: 6 mar. 2013.

LEITE, José Maria, nds. Théomir Devaux, l'histoire d'une fidélité. Informa-Sion Paris, n. 18, p. 3-9, 2007. Disponível em: http://www.congregation-sion.org//MG/pdf/ petheomirdevaux-JML.pdf. Acesso em : 12 mar. 2013.

ROTA, Olivier. L'Association de Prières pour Israël (1903-1966). Bulletin du Centre de recherches français à Jérusalem, Jerusalém, n. 13, p. 6-21, 2003 (en ligne) Disponível em: 〈http://bcrfj.revues.org/134〉. Acesso em: 20 mar. 2013.

SIDIC-PARIS. Nossa história. Disponível em: «http://www.sidic-paris.org/sidic40ans/ histoire/histoire2.pdf〉. Acesso em: 09 mar. 2013.

VATICANO II. Decreto Presbyterorum ordinis, 7 de dezembro de 1965a. Disponível em: 〈http://www.vatican.va/archive/hist_councils/ii_vatican_council/documents/vatii_decree_19651207_presbyterorum-ordinis_po.html〉. Acesso em: 8 mar. 2013.

VATICANO II. Declaração Nostra AEtate, Roma, 28 out. 1965b. Disponível em: 〈http://www.vatican.va/archive/hist_councils/ii_vatican_council/documents/vatii_ decl_19651028_nostra-aetate_fr.html〉. Acesso em: 13 mar. 2013. 